\title{
Rhapsody in emerald: phylogenetic framework for Lestidae with reference to the systematic position of Chalcolestes Kennedy
}

\author{
Thomas J. Simonsen ${ }^{1,2^{*}}$, Marcus Glahder ${ }^{3}$, Thomas Pape ${ }^{3}$, \\ Kent Olsen $^{1} \&$ Marie Djernæs ${ }^{1,2}$ \\ ${ }^{1}$ Natural History Museum Aarhus, 8000 Aarhus C, Denmark \\ ${ }^{2}$ Department of Biology, Aarhus University, 8000 Aarhus C, Denmark \\ ${ }^{3}$ Natural History Museum of Denmark, University of Copenhagen, 2100 Copenhagen, Denmark \\ *Corresponding author. Email: t.simonsen@nathist.dk
}

Research Article

○ OPEN ACCESS

This article is distributed under the terms of the

Creative Commons

Attribution License,

which permits unrestricted use, distribution, and reproduction in any medium, provided the original author and source are credited.

Published: 10 January 2022 Received: 24 September 2021

Accepted: 9 December 2021

Citation:

Simonsen, Glahder, Pape, Olsen \& Djernæs (2022):

Rhapsody in emerald: phylogenetic framework for Lestidae with reference to the systematic position of Chalcolestes Kennedy. International Journal of Odonatology, 25, 16-21 doi:10.48156/1388.2022.1917157

Data Availability Statement: All relevant data are within the paper and its Supporting Information files.

\begin{abstract}
We reconstruct a phylogenetic framework for the zygopteran family Lestidae based on a molecular dataset comprised of sequence data from the genes COI, 16S, 18S, $28 \mathrm{~S}$, and ITS1+2 from 41 ingroup taxa and 8 outgroup taxa with emphasis on the systematic position of the genus Chalcolestes Kennedy. We recover Lestidae as monophyletic with good statistical support. The family falls into two subequal clades. One, comprising the genus Sympecma Burmeister and Lestes Leach sensu lato (including the genus Archilestes Selys) is poorly to moderately supported. While the other, comprising the genera Austrolestes Tillyard, Indolestes Fraser, Orolestes McLachlan, and Chalcolestes is strongly supported. Chalcolestes is recovered as sister to the Oriental genus Orolestes with strong support. Our results thus support that Chalcolestes is a valid genus not closely related to Lestes. Monophyly of Lestes requires inclusion of the New World genus Archilestes, and our results support the need for a thorough revision of Lestes.
\end{abstract}

Key words. Archilestes, Austrolestes, Lestes, Orolestes, molecular phylogeny

\section{Introduction}

Lestidae or emerald damselflies are a small, cosmopolitan zygopteran family comprising nine recognised genera with approximately 150 species (Bridges, 1994; Dijkstra \& Kalkman, 2012; Vajda et al., 2018; Paulson \& Schorr, 2021). Many-but certainly not all-are metallic green (Figure 1 ) and often rest with the left and right wings held at approximately 45 degrees to each other providing the basis for the vernacular names 'emerald damselflies' or 'spread-winged damselflies'. More than half of the species are currently placed in the genus Lestes Leach, 1815 (Paulson \& Schorr, 2021), a heterogeneous genus in dire need of a phylogenetically based revision (Dijkstra \& Kalkman, 2012). To date the only higher-level systematic arrangement proposed for the family has been the division of the family into two subfamilies, viz. Lestinae and Sympecmatinae (Fraser, 1951), with the former comprising the genera Lestes, Archilestes Selys, 1862, Orolestes McLachlan, 1895, Perilestes Hagen, 1862, Sinhalestes Fraser, 1951, and Chalcolestes Kennedy, 1920; and the latter comprising Sympecma Burmeister, 1839, Austrolestes Tillyard, 1913, and Indolestes Fraser, 1922. However, many authors (e.g. Rehn, 2003; Bybee et al., 2008; Carle et al., 2008; Dumont et al., 2010; Dijkstra \& Kalkman, 2012; Dijkstra et al., 2013; Kim et al., 2014) do not follow this subfamily arrangement, and Djikstra et al. (2014) found that while Austrolestes and Indolestes came out as sister groups in their analyses, they were not closely related to Sympecma. While there has been no 
comprehensive phylogenetic analysis of Lestidae, some of the studies above-all focused on higher-level Odonata or Zygoptera relationships-have included several members of Lestidae. Rehn (2003) found that Sympec$m a$ is the sister group to a clade comprising Archilestes, Lestes, and Austrolestes based on morphology, while Bybee et al. (2008) recovered the conflicting result that Austrolestes is the sister to a clade comprising Sympecma, Lestes, and Archilestes based on DNA. In a molecular study, Dumont et al. (2010) found that Sympecma is sister to a clade comprising Indolestes and Chalcolestes, while Lestes sensu lato emerged as paraphyletic with respect to all other Lestidae included in the analyses. Kim et al. (2014) were the first to include Indolestes in a molecular phylogeny and found it to be sister to Sympecma, but they only included Lestes as a third representative of Lestidae. Dijkstra et al. (2014) in their molecular phylogeny of Zygoptera included Indolestes, Austrolestes, Sympecma, and six species of Lestes. They found that Sympecma is the sister to a monophyletic Lestes, and that clade is the sister to a clade comprising Indolestes and Austrolestes. Bybee et al. (2021) in the first comprehensive phylogenomic analysis of Odonata found that Indolestes and Austrolestes are sisters, and Orolestes is the sister to that clade, with Sympecma being the sister to Orolestes + (Indolestes + Austrolestes). The sister to that clade is a clade comprising Lestes and Archilestes.

Chalcolestes is one of the smallest genera in the family, comprising the two Palaearctic species $C$. viridis (Vander Linden, 1825) and C. parvidens (Artobelevski, 1929). It was separated from Lestes by Kennedy (1920) based on the shape of the nymphal prementum, which is broad in Chalcolestes and narrow in Lestes (e.g. Gyulavári et al., 2011). Chalcolestes further differs from Lestes in having a unique egg-laying behaviour where the female oviposits in branches overhanging waterbodies (e.g. Askew, 2004; Gyulavári et al., 2011). However, Chalcolestes is not universally accepted as a separate genus and some works (e.g. Askew, 2004; Smallshire \& Swash 2010) still list viridis and parvidens under Lestes. Only Dumont et al. (2010) among the higher-level phylogenetic studies of Zygoptera included Chalcolestes in their dataset, and as mentioned above, they did not find evidence for a close relationship between Chalcolestes and Lestes. This was confirmed by Gyulavári et al. (2011) based on DNA, and by Vajda et al. (2018) based on adult morphology, although these studies included only European species and were thus restricted to the three genera Lestes, Chalcolestes, and Sympecma.

To clarify the systematic position and taxonomic status of Chalcolestes we here analyse the phylogenetic relationships of 39 species of Lestidae representing seven of the recognised nine genera based on DNA sequences from the mitochondrial genes $\mathrm{COI}$ and $16 \mathrm{~S}$, and the nuclear genes ITS1+2, 5.8S, 18S, 28S, and EF1- $\alpha$. We further address the phylogenetic position of Sympecma, and test the monophyly of Lestes.

\section{Material and methods Taxon sampling}

The total dataset is comprised of 41 ingroup and eight outgroup taxa (Supplementary material S1). Our sampling of Lestidae includes representatives of the genera Archilestes, Austrolestes, Chalcolestes, Indolestes, Lestes, Orolestes, and Sympecma, with most specimens belonging to Lestes. Our outgroup sampling includes the lestoid genera Megalestes Selys, 1862, Nubiolestes Fraser, 1945, Perilestes Hagen, 1862, Perissolestes Kennedy, 1941, and Synlestes Selys, 1868, as well as Calopteryx Leach, 1815, Enallagma Charpentier, 1840, and Platycnemis Burmeister, 1839 (all Zygoptera). The data set consists of a mixture of sequences from GenBank and BOLD (Barcode of Life Data System) combined with new sequences produced for the present study (see Supplementary material S1 for further details).

DNA extraction was done as described in Simonsen et al. (2020) as was sequencing of the COI barcode fragment and ITS1+2 (comprised of ITS1, 5.8S and ITS2). The 28S D2 loop was amplified using the PCR protocol of Simonsen et al. (2020) and the primers D2-F2 (with universal tail): TGTAAAACGACGGCCAGTGGTTGCTTGAGAGTGCAGCCC (tail in boldface) and D2-R2 (with universal
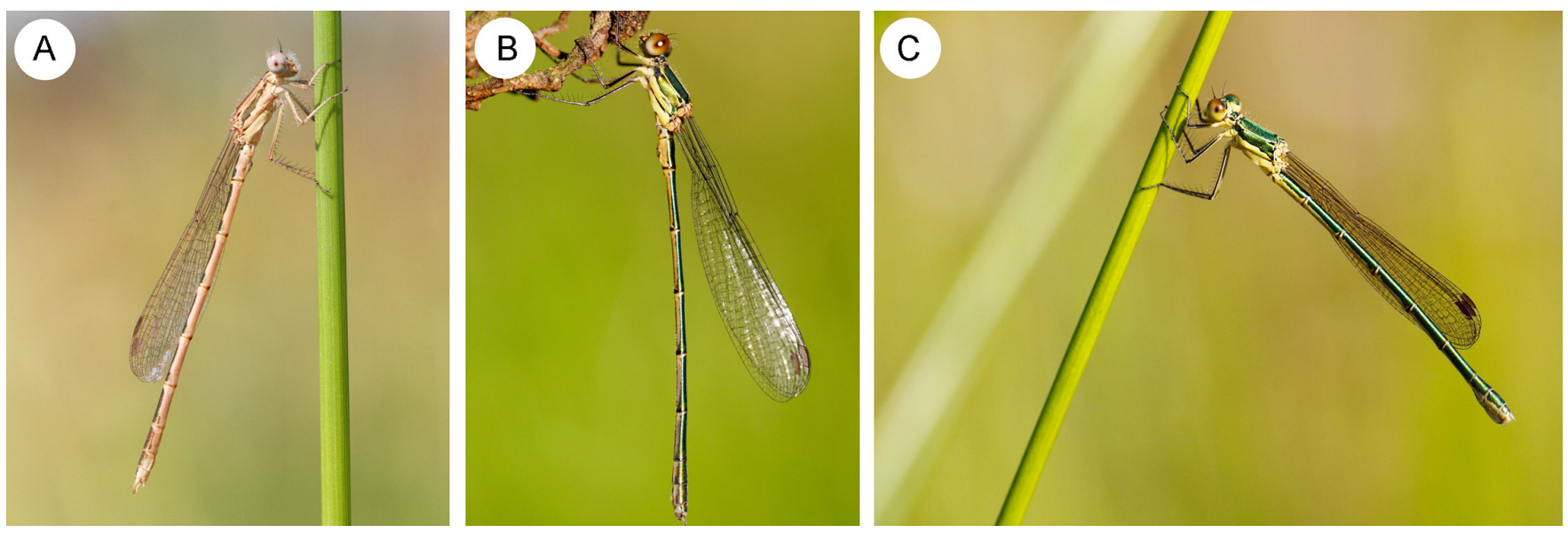

Figure 1. Examples of adult diversity in Lestidae. (A) Sympecma fusca; (B) Chalcolestes viridis; (C) Lestes virens (photo: Kent Olsen). 
tail): CAGGAAACAGCTATGACCATGTTAGACTCCTTGGTCCG (tail in boldface). Both primers were developed for this study. Samples were sequenced at Macrogen Europe using the Sanger method. Contigs and consensus sequences were produced in DNA Baser Sequence Assembler v5.8.0 (Heracle Biosoft, 2018). The identity of all sequences were checked using BLAST on GenBank and/or BOLD Identification System.

Sequences were aligned in MEGA X (Kumar et al., 2018) using the implemented Muscle algorithm. Alignments were subsequently checked by eye in Mesquite v. 3.03 (build 702; Maddison \& Maddison, 2015) and the alignment of ITS1+2 was manually corrected.

The combined aligned dataset is comprised of $6430 \mathrm{bp}$ for a maximum of $658 \mathrm{bp} \mathrm{COI}, 553 \mathrm{bp} \mathrm{16S}$, 1839 bp 28S, 1979 bp 18S, and 1401 bp ITS1+2.

A full list of species and GenBank numbers for each sequence is provided in Supplementary material S1.

We partitioned the data set by gene with ITS1+2 treated as a single gene, resulting in five partitions. We performed Bayesian Inference analysis in MrBayes 3.2 (Ronquist et al., 2012) using model jumping with a gamma model for variation across sites (nst $=$ mixed rates $=$ gamma). Model jumping is a recommended alternative to $a$ priori model testing as it allows MrBayes to sample across the entire GTR model space (Ronquist et al., 2012). The analysis was run for 10 million generations with sampling every 1000 generations and burninfrac set to 0.5 .

We performed Maximum Likelihood analyses in Garli 2.01 (Zwickl, 2006) on Cipres XCEDE (Miller et al., 2010). We used the GTR submodel with the highest posterior probability from the MrBayes analysis for each partition. Models and the overall rate (subsetspecificrates) were unlinked across partitions. We specified Calopteryx splendens (Harris, 1782) as outgroup. Ten independent runs of the analysis were done and the analyses were terminated after 20,000 generations without significant change of topology. A majority rule consensus tree was produced in Mesquite. The Bootstrap analysis was run with 1000 bootstrap repetitions and one search repetition per bootstrap repetition, settings otherwise as above. Bootstrap values were calculated in Mesquite.

The full dataset for the MrBayes analysis is provided in the NEXUS format as Supplementary material S2. The $\mathrm{ML}$ majority rule consensus tree and bootstrap tree are provided in Supplementary material S3-S4.

\section{Results}

The Bayesian phylogram from MrBayes and the consensus tree from the ten ML analyses in Garli are remarkably similar with only two minor differences, which are discussed below. The phylogram from the MrBayes analysis with posterior probabilities and ML bootstrap values is shown in Figure 2. The ML trees from the Garli analyses are provided in Supplementary materials S3-S4.

Lestidae are monophyletic and well supported (BS = $95, \mathrm{PP}=1$ ) in both sets of analyses. The family may be divided into two monophyletic subgroups, hereafter termed Group 1 and Group 2. Group 1 is strongly supported $(\mathrm{BS}=89, \mathrm{PP}=1)$ and comprised of Chalcolestes, Orolestes, Austrolestes, and Indolestes. Group 1 may be further subdivided into two groups, one comprising Chalcolestes and Orolestes, and one comprising Austrolestes and Indolestes. The sister-group relationship between Chalcolestes and Orolestes is strongly supported $(B S=98, P P=1)$, and each genus is monophyletic with strong support ( $B S=100, P P=1$ for both). The group comprising Austrolestes and Indolestes is well supported $(\mathrm{BS}=91, \mathrm{PP}=1)$, but the position of $A$. colensonis (White, 1846) differs between the Bayesian and ML analyses. In the Bayesian analysis $A$. colensonis emerges in a trichotomy at the base of Indolestes. In the $\mathrm{ML}$ analyses $A$. colensonis is the sister to the remaining Austrolestes, and Indolestes is the sister group to Austrolestes. However, both arrangements are poorly supported. Group 2 is comprised of Sympecma, Archilestes, and Lestes sensu lato, with Sympecma being the sister group to a large clade comprising Archilestes and Lestes sensu lato. Group 2 does not receive a BS above 50 and is therefore not recovered in the ML bootstrap tree, but it does receive a moderate support in the Bayesian analysis (PP $=0.88)$. Sympecma is monophyletic and strongly supported $(B S=100, P P=1)$. Lestes sensu lato is paraphyletic with respect to Archilestes, but the group comprising the two genera is moderately to well supported $(\mathrm{BS}=74, \mathrm{PP}=0.98$ ). Within this group the two species L. pallidus Rambur, 1842 and L. pinheyi Fraser, 1955 form a moderately to well supported (BS = $60 \mathrm{PP}=97$ ) sister group to a poorly supported $(\mathrm{BS}<50$, $\mathrm{PP}=0.77$ ) group comprising the remaining species. Within the latter group, the three species $L$. dissimulans Fraser, 1955, L. praemorsus Hagen, 1862 and L. umbrinus Selys, 1891 form a well-supported $(B S=77, P P=1)$ group that is sister to a poorly to moderately supported (BS $=53, P P=0.87$ ) group comprising Archilestes and the remaining Lestes, which we term Lestes sensu stricto. Finally, Archilestes, represented by A. grandis (Rambur, 1842), is the sister to Lestes sensu stricto, with the latter being poorly to moderately well supported (BS = $53, \mathrm{PP}=0.87)$. We discuss the internal relationships of Lestes sensu stricto below, but note that the two sets of analyses differ only with respect to the relationships between Lestes numidicus Samraoui, Weekers \& Dumont, 2003 and the two subspecies of Lestes virens, viz. $L$. virens virens Charpentier, 1825 and $L$. virens vestalis Rambur, 1842. In the Bayesian analysis L. virens is monophyletic, while in the $\mathrm{ML}$ analyses $L$. virens vestalis is sister to a clade comprising $L$. virens virens and L. numidicus.

\section{Discussion \\ Phylogenetic topology}

Our overall results are similar to those of Dijkstra et al. (2014), where a clade comprising Indolestes + Austro- 
lestes was recovered as a sister group to Sympecma + Lestes sensu lato. In contrast to this Dumont et al. (2010), Kim et al. (2014), and Bybee et al. (2021) all found Sympecma to be closely related to a clade comprising Indolestes and-depending on taxon samplingAustrolestes, Orolestes, and Chalcolestes. While the sister-group relationship between Sympecma and Lestes sensu lato is well supported in Djikstra et al. (2014), it is only moderately supported in our Bayesian analysis, and not supported at all in our ML analyses. The clade comprising Chalcolestes, Orolestes, Austrolestes, and Indolestes is well supported here and in agreement with previous studies. A clade comprising Indolestes and Austrolestes was also found by Dijkstra et al. (2014) and Bybee et al. (2021). We consistently recover only Indolestes as monophyletic, but our taxon and character sampling is too limited to provide a firm conclusion on Austrolestes.

We recover Lestes sensu lato including Archilestes as monophyletic with good support in both the Bayesian and ML analyses. This is in agreement with Djikstra et al. (2014), but in conflict with Dumont et al. (2010), who recovered Lestes pinheyi as the sister to the re- maining Lestidae. Similar to Dijkstra et al. (2014) we recover a clade comprising $L$. pinheyi and L. pallidus as sister group to the remaining Lestes sensu lato. Unlike previous studies we find that Lestes in the traditional circumscription is paraphyletic, because Archilestes is the sister taxon to a subset of Lestes, the latter is here termed Lestes sensu stricto. Although our taxon sampling within Lestes sensu lato is limited to less than half the species currently placed in the genus (Dijkstra \& Kalkman, 2012; Paulson \& Schorr, 2021), the results clearly support the statement by Dijkstra \& Kalkman (2012) that Lestes is in dire need of a phylogeny-based revision, and we further suggest that Archilestes should be included in such a revision.

Our results support Dijkstra et al. $(2013,2014)$ in that there is little support for retaining subfamily division within Lestidae, and we find in particular no support for Sympecmatinae comprising Sympecma, Austrolestes, and Indolestes. While there may be support for a subfamily division into three subfamilies, with one comprising Lestes sensu lato, one comprising Sympecma, and one comprising Chalcolestes, Orolestes, Indolestes, and Austrolestes, we consider our taxon sampling too

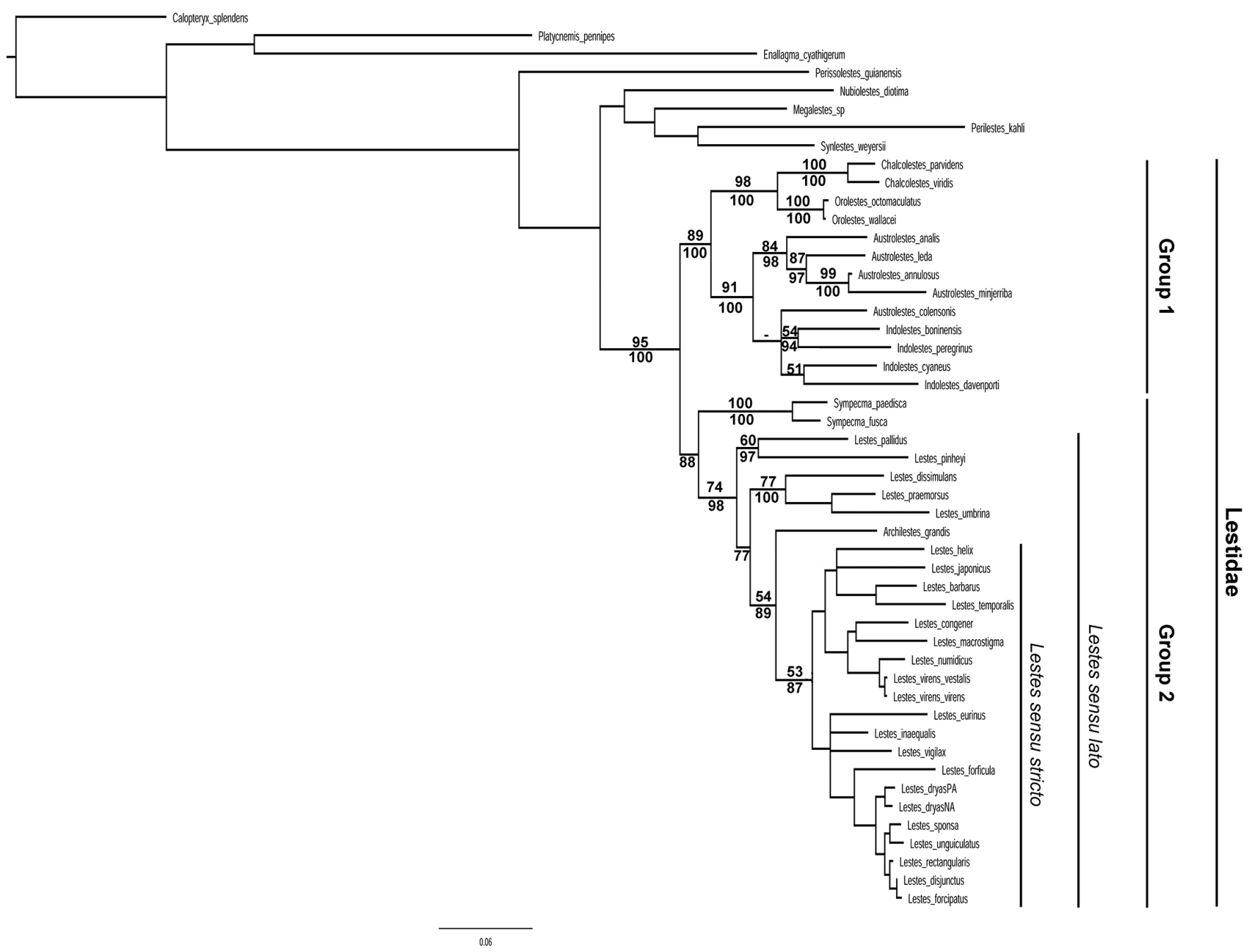

Figure 2. Phylogram from the 10 million generation Bayesian analysis of the combined dataset. Numbers above a line indicate ML bootstrap values $\geq 50$, while numbers below a line indicate posterior probabilities $\geq 75$. A dash (-) indicates that the group was not recovered in the ML analyses (internal values for Lestes sensu stricto not provided). 
limited to propose such an arrangement as we have not been able to include the genera Platylestes and Sinhalestes in our dataset.

\section{Position of Chalcolestes}

Our results support recent conclusions by Dumont et al. (2010), Gyulavári et al. (2011), Dijkstra and Kalkman (2012), and Vajda et al. (2018) that Chalcolestes is a valid genus and should not be considered a synonym of Lestes. Gyulavári et al. (2011) analysed COI and ITS sequences from several specimens of $C$. viridis and C. parvidens, as well as Sympecma fusca and six taxa of European Lestes spp. in two separate analyses. In both analyses they found that Chalcolestes and Lestes are separated by Sympecma. However, as they did not analyse a combined dataset and only included European species, their results provide little information on the phylogenetic position of Chalcolestes. More importantIy, their datasets did not include any non-Lestidae outgroup taxa and if the trees they presented (Gyulavári et al., 2011, fig. 3) are rooted on Sympecma fusca (Vander Linden, 1820), Chalcolestes and the included representatives of Lestes would appear to be sister groups. Even though Vajda et al. (2018) could not conclusively separate Chalcolestes, Lestes, and Sympecma in their statistical morphometric analyses of male morphology, they concluded that differences in the male secondary genitalia structures support full genus status for Chalcolestes. Furthermore, they mentioned that female genitalia morphology also supports this, as Chalcolestes viridis has two spermathecae, Sympecma fusca one spermatheca, and at least Lestes barberus (Fabricius, 1798 ) and Lestes virens have no spermatheca (Vajda et al., 2018, p. 254). As mentioned above, Dumont et al. (2010) is the only higher-level phylogenetic study that includes Chalcolestes. Their results are similar to ours as Chalcolestes is the well-supported sister group to Indolestes. Our taxon sampling within Lestidae is broader than that of Dumont et al. (2010) as we include the genera Orolestes and Austrolestes. We find that Indolestes is placed in a strongly supported monophyletic group with Austrolestes, and that Chalcolestes is placed in a strongly supported monophyletic group with Orolestes. As these two groups together form a strongly supported monophyletic group (Group 1), our results are compatible with Dumont et al. (2010), and strongly support full genus status for Chalcolestes. Interestingly, Chalcolestes is entirely restricted to the Western and Central Palaearctic (Boudot \& Duatlova, 2015; Boudot \& Willigalla, 2015), while the other three genera are found in Southeast Asia (Orolestes), Australia (Austrolestes), or from India to Japan and Australia (Indolestes) (GBIF.org, 24 September 2021). As our dataset does not include the genera Platylestes (India, Southeast Asia) and Sinhalestes (Sri Lanka) (GBIF.org, 24 September 2021), we refrain from making any biogeographical conclusions but note that Chalcolestes may represent a dispersal into Central and Western Palaearctic by an otherwise Oriental-Australian group.

\section{Conclusions and further directions}

Three main conclusions can be drawn from our results despite the somewhat limited taxon sampling. First, there is no phylogenetic support for dividing Lestidae into the subfamilies Lestinae and Sympecmatinae. Second, Lestes as currently defined is almost certainly not a monophyletic group, and we agree with Dijkstra and Kalkman (2012) that a phylogenetic revision of the genus is much needed. Third, Chalcolestes is a valid genus that is not closely related to other European genera of Lestidae-neither Lestes nor Sympecma. Instead, the genus is most likely the sister group to Orolestes and placed in a clade with otherwise Oriental-Australian genera.

Other than the much-needed revision of Lestes sensu lato, several high profile aspects of Lestidae phylogeny and systematics remain to be solved. The relationship and delimitation of Austrolestes and Indolestes remain unclear, and the two genera in combination should be the subject of a phylogenetic taxonomic revision. The higher-level phylogeny of Lestidae should be the subject of phylogenomic analyses in the mould of Bybee et al. (2021) and include also Platylestes and Sinhalestes. Such a study should address the phylogenetic position of Sympecma, identify natural divisions that can be used for a subfamily and tribal classification, and resolve the biogeography of the family including the geographical origin of Chalcolestes.

\section{Acknowledgements}

We thank Annie Brandstrup, Aarhus University (Denmark), for assistance in the DNA lab. We thank Joaquin Baixeras, University of Valencia (Spain), Arne Drews, Nature Conservation Schleswig-Holstein (Germany), and Ole Fogh Nielsen (Denmark) for providing specimens for sequencing. We thank two anonymous reviewers for comments and suggestions that greatly improved the manuscript. Funding was provided by the Research Fund under the Danish Ministry for Culture (Grant: FORM.2015-0023), the 15 June Foundation (Grant: 2015-A-89), Schjøtz-Christensen's Memorial Fund (Denmark), and the EU SYNTHESYS Program (SE-TAF-5543).

\section{References}

Askew, R. R. (2004). The Dragonflies of Europe (revised edition). Harley Books, Colchester. https://doi.org/10.1111/j.10963642.2006.00265.x. doi:10.1111/j.1096-3642.2006.00265.x

Boudot, J.-P. \& Dyatlova, E. (2015). Chalcolestes parvidens (Artobelevskij, 1929). In Boudot, J.-P. \& Kalkman, V. J. (Eds.), Atlas of the European Dragonflies and Damselflies. pp. 52-53. KNNV Publishing, The Netherlands.

Boudot, J.-P. \& Willigalla, C. (2015). Chalcolestes viridis (vander Linden, 1825). In Boudot, J.-P. \& Kalkman, V. J. (Eds.), Atlas of the European Dragonflies and Damselflies. pp. 53-54. KNNV Publishing, The Netherlands. 
Bridges, C. A. (1994). Catalogue of the family-group, genus-group and species-group names of the Odonata of the World (third edition). Illinois Natural History Survey, Urbana, Illinois, USA. doi:10.5962/bhl.title.15291

Bybee, S. M., Kalkman, V. J., Erickson, R. J., Frandsen, P. B., Breinholt, J. W., Suvorov, A., Dijkstra, K.-D. B., Cordero-Rivera, A., Skevington, J. H., Abbott, J. C., Sanchez-Herrera, M., Lemmon, A. R., Lemmon, E. M. \& Ware, J. L. (2021). Phylogeny and classification of Odonata using targeted genomics. Molecular Phylogenetics and Evolution, 160, 107115. doi:10.1016/j.ympev.2021.107115

Bybee, S. M., Ogden, T. H., Branham, M. A. \& Whiting, M. F. (2008). Molecules, morphology and fossils: a comprehensive approach to odonate phylogeny and the evolution of the odonate wing. Cladistics, 24, 477-514. doi:10.1111/j.1096-0031.2007.00191.x

Carle, F. L., Kjer, K. M. \& May, M. L. (2008). Evolution of Odonata, with special reference to Coenagrionoidea (Zygoptera). Arthropod Systematics \& Phylogeny, 66, 37-44.

Dijkstra, K.-D. B., Bechly, G., Bybee, S. M., Dow, R. A., Dumont, H. J., Fleck, G., Garrison, R. W., Hämäläinen, M., Kalkman, V. J., Karube, H., May, M. L., Orr, A. G., Paulson, D. R., Rehn, A. C., Theischinger, G., Trueman, J. W. H., van Tol, J., von Ellenrieder, N. \& Ware, J. L. (2013). The classification and diversity of dragonflies and damselflies (Odonata), Animal Biodiversity: An Outline of Higher-level Classification and Survey of Taxonomic Richness, (ed. by Z.-Q. Zhang). Zootaxa, 3703, 36-45. doi:10.11646/zootaxa.3703.1.9

Dijkstra, K.-D. B. \& Kalkman, V. J. (2012). Phylogeny, classification and taxonomy of European dragonflies (Odonata): a review. Organisms Diversity \& Evolution, 12, 209-227. doi:10.1007/ s13127-012-0080-8

Dijkstra, K.-D. B., Kalkman, V. J., Dow, R. A., Stokvis, F. R. \& van Tol, J. (2014). Redefining the damselfly families: a comprehensive molecular phylogeny of Zygoptera (Odonata). Systematic Entomology, 39, 68-96. doi:10.1111/syen.12035

Dumont, H. J., Vierstraete, A. \& Vanfleteren, J. R. (2010). A molecular phylogeny of the Odonata (Insecta). Systematic Entomology, 35, 6-18. doi:10.1111/j.1365-3113.2009.00489.x

Fraser, F. C. (1951). Outline of a new classification for the region Lestes Selys (Order Odonata). Entomological News, 62, 61-69.

GBIF.org (24 September 2021) GBIF Occurrence Download. https:// doi.org/10.15468/dl.xsa77g

Gyulavári, H. A., Felföldi, T., Benken, T., Szabó, L. J., Miskolczi, Cserháti, C., Horvai, V., Máriallgeti, K., Dévai, G. (2011). Morphometric and molecular studies on the populations of the damselflies Chalcolestes viridis and C. parvidens. International Journal of Odonatology, 14, 329-339. doi:10.1080/13887890.2011.651983

Heracle Biosoft (2018). Automatic DNA Baser Sequence Assembler, v5. www.dnabaser.com

Kennedy, C. H. (1920). Forty-two hitherto unrecognised genera and subgenera of Zygoptera. The Ohio Journal of Science, 21, 83-88. doi:10.5962/bhl.part.14540

Kim, M. J., Jung, K. S., Park, N. S., Wan, X., Kim, K.-G., Jun, J., Yoon, T. J., Bae, Y. J., Lee, S. M. \& Kim, I. (2014). Molecular phylogeny of the higher taxa of Odonata (Insecta) inferred from COI, 16S rRNA, 28S rRNA, and EF1- $\alpha$ sequences. Entomological Research, 44, 65-79. doi:10.1111/1748-5967.12051

Kumar, S., Stecher, G., Li, M., Knyaz, C., Tamura, K. (2018). MEGA $\mathrm{X}$ : Molecular Evolutionary Genetics Analysis across computing platforms. Molecular Biology and Evolution, 35, 1547-1549. doi:10.1093/molbev/msy096

Maddison, W. P. \& Maddison, D. R. (2015). Mesquite: A modular system for evolutionary analysis. Version 3.03. http://mesquiteproject.org

Miller, M. A., Pfeiffer W. \& Scharwartz T. (2010). Creating the CIPRES science gateway for inference of large phylogenetic trees.
Proceedings of the Gateway Computing Environments Workshop (GCE), New Orleans, 1-8. doi:10.1109/GCE.2010.5676129

Paulson, D. \& Schorr, M. (2021). World Odonata List. Retrieved July, 06, 2021, from https://www2.pugetsound.edu/academics/academic-resources/slater-museum/biodiversity-resources/dragonflies/world-odonata-list2/

Rehn, A. C. (2003). Phylogenetic analysis of higher-level relationships of Odonata. Systematic Entomology, 28, 181-240. doi:10.1046/ j.1365-3113.2003.00210.x

Ronquist, F., Huelsenbeck, J. \& Teslenko, M. (2012). Draft Mr Bayes version 3.2 Manual: Tutorials and Model Summaries. Online publication available from the authors.

Simonsen, T. J., Olsen, K. \& Djernæs, M. (2020). The African-Iberian connection in Odonata: mtDNA and ncDNA based phylogeography of Aeshna cyanea (Müller, 1764) (Odonata: Aeshnidae) in Western Palaearctic. Arthropod Systematics and Phylogeny, 78, 309-320. doi: 10.26049/ASP78-2-2020-06

Smallshire, D. \& Swash, A. (2010). Britain's Dragonflies. A fieldguide to the damselflies and dragonflies of Britain and Ireland $\left(2^{\text {nd }}\right.$ edition). WildGuides, Old Basing.

Vajda, C., Szabó, L. J., Cserháti, C. \& Dévai, G. (2018). Analysing the European genera of family Lestidae (Odonata: Zygoptera) with special emphasis on the status of Chalcolestes based on the morphological characteristics of male adults. International Journal of Odonatology, 21, 241-259. doi:10.1080/13887890.2018.15472 24

Zwickl, D. J. (2006). Genetic algorithm approaches for the phylogenetic analysis of large biological sequence datasets under the maximum likelihood criterion. [Unpublished doctoral dissertation]. The University of Texas at Austin.

\section{Supplementary material}

Supplementary material S1. List of taxa and GenBank accession numbers included in the study.

Supplementary material S2. NEXUS file used in the 10 million generation analysis in MrBayes.

Supplementary material S3. Majority Rule consensus tree from $10 \mathrm{ML}$ analyses in Garli.

Supplementary material S4. Majority Rule bootstrap tree from 1000 random replications in Garli. 